\title{
Çameli Depremi (5.1) Artçı Şoklarının Çift Fark Algoritması İle İncelenmesi
}

\author{
Fahriye AKAR* \\ Erzincan Üniversitesi, İnşaat Teknolojileri Bölümü, Erzincan \\ (ORCID: 0000-0002-8445-0353)
}

\begin{abstract}
$\ddot{O} \mathbf{z}$
Çameli bölgesi Burdur-Fethiye Fay Zonu'nun orta kesiminde bulunan aktif tektonik bölgelerden biridir. 20072008 yıllarında mikrodeprem aktivitesinde artış gözlenmiştir. Bu depremlerin en büyüğü 29 Ekim $2007(\mathrm{ML}=5.1)$ Çameli Depremidir. TÜBİTAK Yer ve Deniz Bilimleri Enstitüsü ile Afet İşleri Genel Müdürlüğü Deprem Araştırma Dairesinin (AFAD) ortaklaşa yürüttükleri 'Deprem Sonrası Acil Gözlem Araştırmaları' projesi kapsamında Çameli Bölgesinde kurulmuş olan 10 adet sismometre ağı ile Çameli Depremi sonrası 700 den fazla deprem kaydedilmiştir. Boğaziçi Üniversitesi Kandilli Rasathanesi, Deprem Araştırma Enstitüsü Ulusal Deprem İzleme Merkezi (BDTİM) tarafından hazırlanan katalogdan Çameli Bölgesi’nde 2007-2008 yılında meydana gelen 1206 adet deprem verisi derlenmiştir. Hem BDTIM' den hem de TÜBİTAK' tan alınan bu veriler incelenmiştir. Depremlerin doğru bir şekilde yeniden konumlandırılması yapılıp çalışma alanı için sismojenik kuşağın derinlikle değişimi tespit edilmiştir. Çameli Depreminin meydana geldiği fayın geometrisi ve odak derinliğinin dağılımı ortaya konulmuştur. Bunun için deprem çifti farkı yöntemi (hypoDD) kullanılmıştır. HypoDD yönteminin uygulanmasıyla her iki veri gurubu içindeki dağınık deprem konumları daha küçük kümelere daralmıştır. Dikey kesitlerden deprem odak derinliklerinin iyileştirilmesiyle sismojenik kabuğun sınırı net bir şekilde görülmüştür. Çameli depreminin artçı şokların 5 ile 15 km derinlikte meydana geldiği yüzeyde ise depremlerin KB-GD ve KDGB yönünde çizgisellik oluşturduğu gözlenmiştir.
\end{abstract}

Anahtar kelimeler: Çameli Depremi, Fay düzlemi çözümü, Artçı şoklar, HypoDD.

\section{Çameli Earthquake (5.1) Investigation of Aftershocks with Double Difference Algorithm}

\begin{abstract}
Çameli region is one of the active tectonic regions in the central part of the Burdur-Fethiye fault zone. In 20072008, micro-earthquake activity increased. The largest of these earthquakes is October 29, $2007(\mathrm{ML}=5.1)$ Çameli Earthquake. In cooperation with TUBITAK Institute of Earth and Marine Sciences and Earthquake Research Department (AFAD) of the General Directorate of Disaster Affairs, 10 seismometers were established in Çameli region within the scope of the 'Earthquake Research After Earthquake Survey Project'. More than 700 earthquakes were recorded after Çameli Earthquake. 1206 earthquakes were collected from the catalog prepared by Boğaziçi University Kandilli Observatory, Earthquake Research Institute National Earthquake Monitoring Center (BDTIM) in 2007-2008. These data were taken from both BDTIM and TÜBITAK. Accurate relocating of the earthquakes and the change of depth of the seismogenic belt to the study area were determined. The geometry of the fault and the distribution of the earthquake focal depth are determined. Double difference method (HypoDD) was used for this. By applying the HypoDD method, the scattered seismic locations were narrowed to smaller clusters for both data groups. The limit of the seismogenic crust was clearly seen by improving the focal depths of the earthquake from the vertical sections. The aftershocks of Çameli earthquake are between 5 and $15 \mathrm{~km}$. This corresponds to the thin brittle portion of the crust. On the surface, it was found that the earthquakes formed a line formation in NW-SE and NE-SW directions.
\end{abstract}

Keywords: Çameli Earthquake, Fault plane solution, aftershocks, HypoDD.

"Sorumlu yazar: fhrykcmzb@ gmail.com

Geliş Tarihi: 30.04.2019, Kabul Tarihi: 23.09.2019 


\section{Giriş}

Çalışma alanı güneybatı Anadolu'da, KD-GB doğrultulu Burdur Fethiye Makaslama Zonu (BFMZ) üzerindedir. $36^{\circ} 45^{\prime} \mathrm{K}$ ve $37^{\circ} 10^{\prime} \mathrm{K}$ enlemleri ile $28^{\circ} 55^{\prime} \mathrm{D}$ ve $29^{\circ} 30^{\prime} \mathrm{D}$ boylamları arasinda yer almaktadır. 29 Ekim 2007 tarihinde meydana gelen Çameli depremi ve artçı şok aktivitesinin analizi için deprem konum parametreleri, deprem çiftleri için gözlenen ve teorik seyahat zamanlarının farkları arasındaki artık zamanların en küçüklenmesi esasına dayanan çift-farklar yöntemi ile yeniden hesaplanmıştır.

Çalışma alanı ofiyolit, mermer ve Likya napları olarak bilinen birimlerin yaygın olarak görüldüğü, doğuda Dirmil Fayı batıda ise Bozdağ Fayı denetiminde KD-GB uzanımında bir graben olarak açılmaya başlamıştır [1-6]. Çameli Havzası, içinde Miyosen yaşlı flüviyal ve gölsel sedimanlar ve Pliyo-Kuvaterner yaşlı birimlerin yer aldığı, KD-GB doğrultulu Burdur Fethiye Makaslama Zonu (BFMZ)'nun [7] bir parçası olarak da tanımlanmaktadır.

Çameli Havzası'nın Geç Miyosen' de Kıbrıs yayı etkisiyle KB-GD gerildiğini ve daha sonra Helen Yayı'nın etkisi ile KD-GB gerilme sistemine geçmiştir [6]. Bölgedeki KKD-GGB yönlü gerilme Gediz Grabeni'ni oluşturan sistemle ilişkilidir [6].

Güneybatı Anadolu'nun yapısal özellikleri ve tektonik evrimi ile ilgili tartışmalar devam etmektedir. Çameli Havzası ve çevresinde gözlemlenen en yaygın fay türleri büyük (km) ve küçük (m) ölçekli normal ve sol yanal oblik normal faylardır. Büyük ölçekli faylara ait fay düzlemleri incelendiğinde genellikle KD-GB doğrultulu oldukları görülmektedir [7].

Çameli depremi (M=5.1) 29 Ekim 2007 tarihinde Denizli iline bağlı Çameli ilçesinin güney batısında gerçekleşmiştir (Şekil 1). Deprem Denizli ve Muğla illerinin birçok köyünde hissedilmiştir. 3 ev yıkılmış, yaklaşık 350 ev hasar görmüştür. Çameli depremi AFAD raporuna göre deprem merkez üssüne $2.67 \mathrm{~km}$ uzaklıktaki en yakın istasyon olan (CAM) ivmeölçer cihazında kaydedilen, ivme kayıtları üzerinden hesaplanan etkin süre K-G bileşeni için pik ivme değeri $56.58\left(\mathrm{~cm} / \mathrm{s}^{2}\right)$ ve etkin süre $t_{\text {eff }}=10.41 \mathrm{sn}, \mathrm{D}-\mathrm{B}$ bileşen için pik ivme değeri $42.81\left(\mathrm{~cm} / \mathrm{s}^{2}\right)$ ve etkin süre $t_{\mathrm{eff}}=15.23 \mathrm{sn}$ 'dir. Ana şoktan bir gün önce 3.0 büyüklüğünde bir öncü deprem meydana gelmiştir. 5.1 büyüklüğündeki depremin ardından 1 gün içinde büyüklükleri 3.4, 4.0 ve 3.1 olan artçı depremler gözlenmiştir.

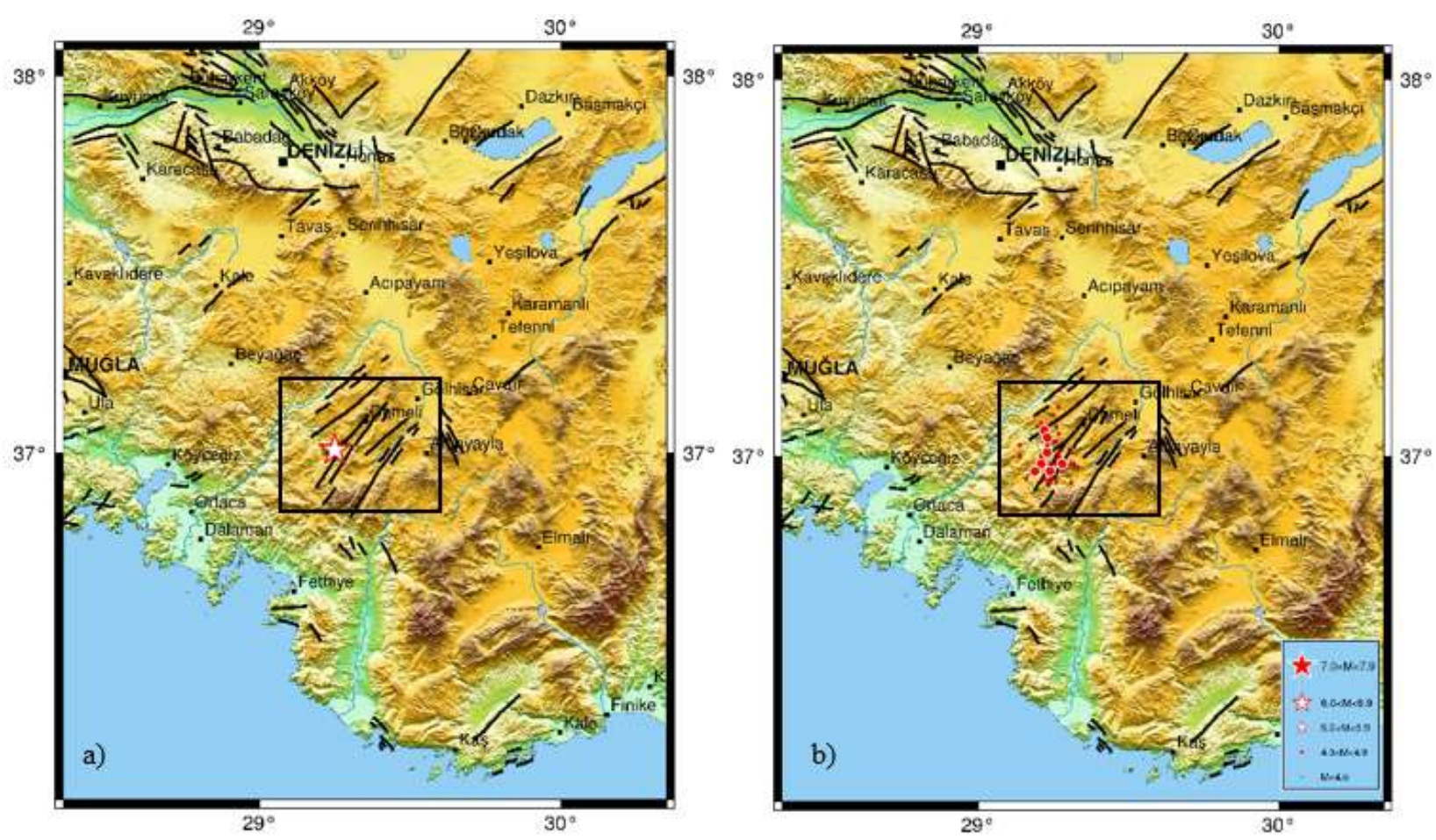

Şekil 1. a) 29 Ekim 2007 Çameli Depremi (5.1) ve b) 29 Ekim 2007-31 Aralık 2007 tarihleri arasında meydana gelen depremler.

Çameli depremi Gölhisar-Çameli Fay zonu ile ilişkili olup, bu zon Gölhisar güneyinde, KelekçiAltınyayla arasında uzanan $40 \mathrm{~km}$ uzunlukta ve $30 \mathrm{~km}$ genişlikte birbirine paralel KD-GB genel gidişli 
üç faydan oluşmaktadır [8]. Çameli depremi, Çameli havzasının güneybatısında meydana gelmiştir. Çameli civarında daha önce 3 Mart 1914 tarihinde 7.1 büyüklügünde Burdur depremi ve 25 Nisan 1957 de büyüklüğü 7.1 olan Fethiye (Muğla) depremi gibi ağır hasara neden olan ve çok geniş bir alanda hissedilen [9] büyük depremler meydana gelmiştir [10]. Bu depremlerle birlikte 1900 y1lından 2000 yılına kadar 10 adet hasar verici deprem meydana gelmiştir [10]. Çalışma alanı Ege-Anadolu bloğunun batıya doğru hareketinin yanı sıra, Girit ve Kıbrıs yitim zonlarıyla ilişkili [11] olduğundan geniş bir alana yayılmış değişik büyüklüklerde bir çok deprem meydana gelmektedir. Şekil 2'de Kandilli Rasathanesi ve Deprem Arastırma Enstitüsü deprem katalogunda yer alan ve 1900 y1lından 2009 y1lına kadar meydana gelmis depremlerin dağılımı görülmektedir. Bölgede KD-GB, KB-GD, D-B ve K-G yönelimli farklı doğrultularda ve birbirini kesen normal faylar yeralmaktadır [12].

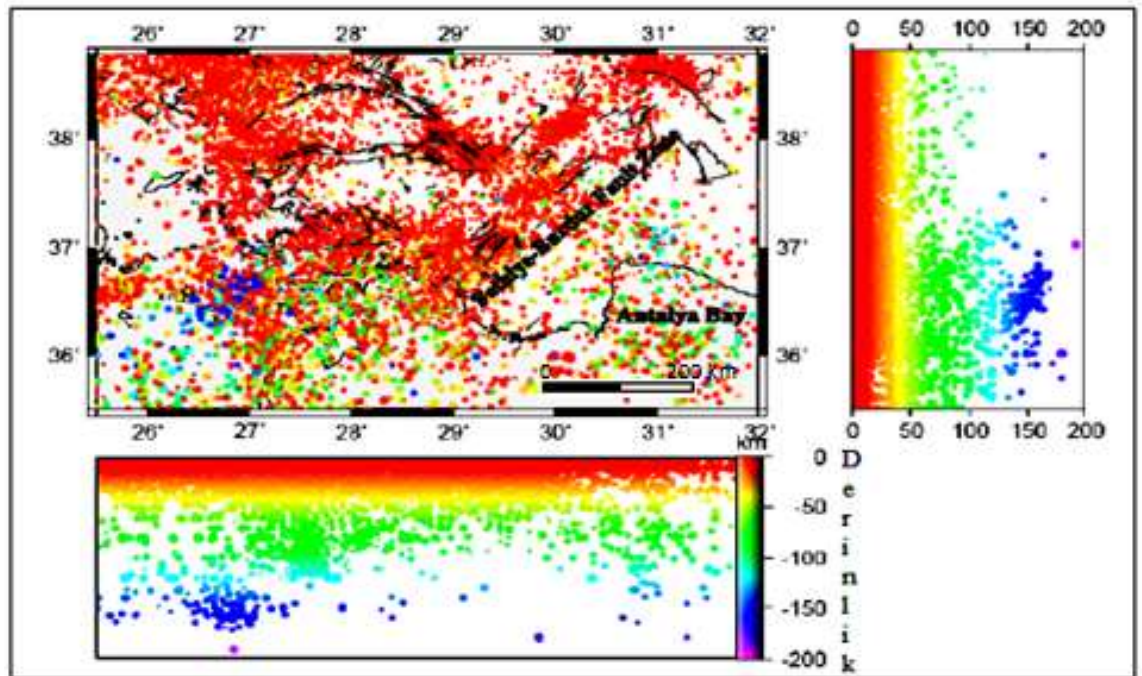

Şekil 2. Güneybatı Anadolu ve Helen yayında 1900-2008 yılları arasında meydana gelen deprem etkinliği [13]

Över vd. [6] Çameli Havzası'ndaki gerilme durumunu belirlemek için 3 Ekim 2007 ve 26 Ekim 2008 tarihleri arasında 3.8-5.3 büyüklüğündeki depremlerin odak mekanizması çözümlerini analiz etmişlerdir (Tablo 1). Mekanizmaların kayma vektörleri oblik atımlı normal faylara karşılık gelmektedir (Şekil 3).

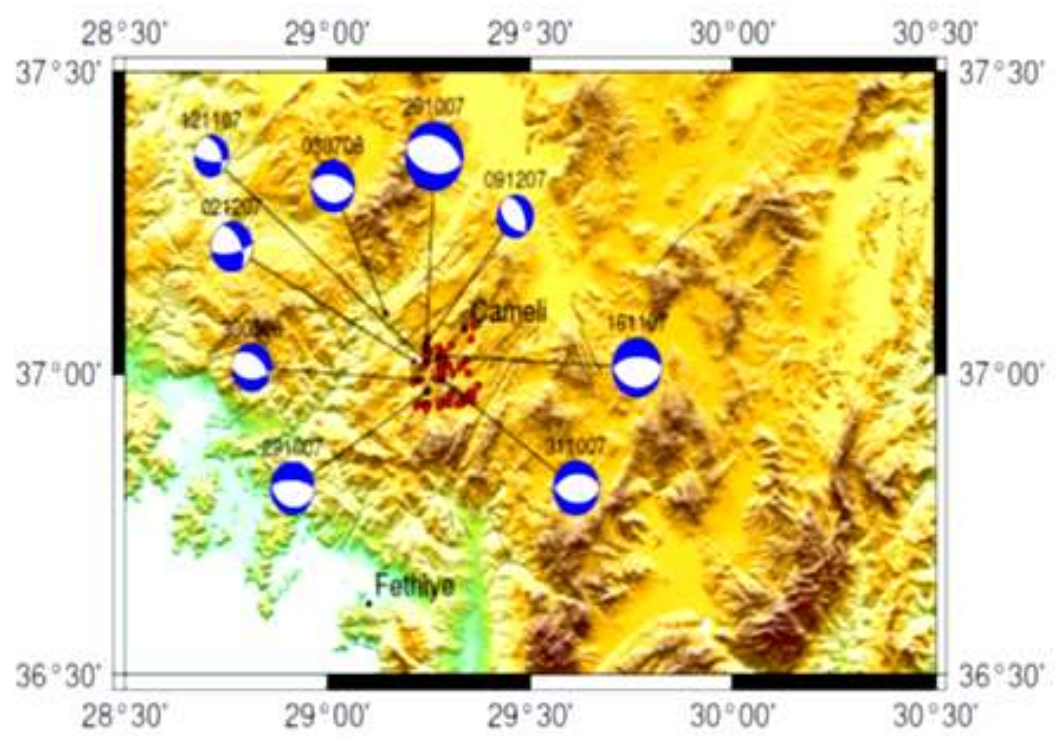

Şekil 3. 29 Ekim 2007 Çameli depremi artçı şokların konumları ve Över vd. [6]'de belirlenen odak mekanizması çözümleri (siyah rakamlar deprem oluş tarihlerini temsil eder) 
Tablo 1. Çameli Havzasında meydana gelen depremlerin odak mekanizması çözümü parametreleri [6]

\begin{tabular}{|c|c|c|c|c|c|c|c|}
\hline $\begin{array}{l}\text { Gün. Ay. } \\
\text { Y11 }\end{array}$ & $\begin{array}{l}\text { Yerel } \\
\text { saat } \\
\text { UTC }\end{array}$ & $\begin{array}{l}\text { Enlem (N) } \\
\text { (Derece, } \\
\text { dakika, } \\
\text { saniye) }\end{array}$ & $\begin{array}{l}\text { Boylam }(\mathrm{E}) \\
\text { (Derece, } \\
\text { dakika, } \\
\text { saniye) }\end{array}$ & $\begin{array}{l}\text { Derin } \\
\text { lik h } \\
(\mathrm{km})\end{array}$ & $\begin{array}{l}\text { Büyük } \\
\text { lük } \\
\left(M_{\mathrm{w}}\right)\end{array}$ & $\begin{array}{l}\text { 1. Düzlem } \\
\text { doğrultu } / \mathrm{e} \\
\text { ğim } \% / \mathrm{kaym}^{\circ} \\
\mathrm{a}^{\circ}\end{array}$ & $\begin{array}{l}\text { 2.Düzlem } \\
\text { doğrultu } / \mathrm{e} \\
\text { ğim } \% / \mathrm{kaym} \\
\mathrm{a}^{\circ}\end{array}$ \\
\hline $\begin{array}{l}29.10 .200 \\
7\end{array}$ & $\begin{array}{l}09.2 \\
3\end{array}$ & $37^{\circ} 01^{\prime} 59^{\prime \prime}$ & $29^{\circ} 13^{\prime} 58^{\prime \prime}$ & 5 & 5.3 & $100 / 48 /-96$ & $289 / 44 /-83$ \\
\hline $\begin{array}{l}29.10 .200 \\
7\end{array}$ & $\begin{array}{l}19.4 \\
1\end{array}$ & $36^{\circ} 58^{\prime} 02^{\prime \prime}$ & $29^{\circ} 13^{\prime} 55^{\prime \prime}$ & 5 & 4.6 & $106 / 26 /-78$ & $273 / 65 /-96$ \\
\hline $\begin{array}{l}31.10 .200 \\
7\end{array}$ & $\begin{array}{l}15.0 \\
2\end{array}$ & $36^{\circ} 59^{\prime} 16^{\prime \prime}$ & $29^{\circ} 16^{\prime} 32^{\prime \prime}$ & 5 & 4.7 & $96 / 44 /-81$ & $264 / 47 /-99$ \\
\hline $\begin{array}{l}12.11 .200 \\
7\end{array}$ & $\begin{array}{l}15.0 \\
2\end{array}$ & $37^{\circ} 00^{\prime} 50^{\prime \prime}$ & $29^{\circ} 13^{\prime} 50^{\prime \prime}$ & 6 & 4.1 & $96 / 66 /-126$ & $337 / 42 /-37$ \\
\hline $\begin{array}{l}16.11 .200 \\
7\end{array}$ & $\begin{array}{l}09.0 \\
8\end{array}$ & $37^{\circ} 01^{\prime} 26^{\prime \prime}$ & $29^{\circ} 15^{\prime} 42^{\prime \prime}$ & 6 & 4.9 & $96 / 31 /-83$ & $268 / 59 /-94$ \\
\hline $\begin{array}{l}02.12 .200 \\
7\end{array}$ & $\begin{array}{l}20.2 \\
1\end{array}$ & $37^{\circ} 01^{\prime} 02^{\prime \prime}$ & $29^{\circ} 12^{\prime} 00^{\prime \prime}$ & 10 & 4.5 & $80 / 68 /-139$ & $332 / 53 /-28$ \\
\hline $\begin{array}{l}09.12 .200 \\
7\end{array}$ & $\begin{array}{l}20.2 \\
9\end{array}$ & $37^{\circ} 02^{\prime} 40^{\prime \prime}$ & $29^{\circ} 13^{\prime} 48^{\prime \prime}$ & 8 & 4.2 & $336 / 50 /-70$ & $\begin{array}{l}126 / 44 /-11 \\
2\end{array}$ \\
\hline $\begin{array}{l}30.05 .200 \\
8\end{array}$ & $\begin{array}{l}05.3 \\
4\end{array}$ & $36^{\circ} 58^{\prime} 54^{\prime \prime}$ & $29^{\circ} 12^{\prime} 48^{\prime \prime}$ & 6 & 4.4 & $306 / 47 /-64$ & $90 / 49 /-115$ \\
\hline $\begin{array}{l}03.07 .200 \\
8\end{array}$ & $\begin{array}{l}17.3 \\
7\end{array}$ & $37^{\circ} 05^{\prime} 40^{\prime \prime}$ & $29^{\circ} 07^{\prime} 49^{\prime \prime}$ & 5 & 4.6 & $280 / 54 /-87$ & $95 / 36 /-9$ \\
\hline
\end{tabular}

Son zamanlarda meydana gelen Çameli deprem etkinliğine bakıldığında, BFMZ' nun Güneybatı ucunda deprem kümelenmesinin yer aldığ 1 söylenebilir. 2007 yılının Ekim ayında ML=5.1 büyüklüğünde büyük deprem meydana gelmiş olup bu depremi yoğun artçı deprem aktiviteleri takip etmiştir. Bunun dışında bölgede $\mathrm{M}>3$ olan çok sayıda deprem meydana gelmiştir. Bu çalışmada, 29 Ekim 2007 Çameli depreminin detaylı artçı analizleri sunulmuştur. Deprem kayıt istasyonu konumları, faz okuma hataları, yeraltı yapısı, depremlerin yerinin doğru bir şekilde belirlenmesinde etkilidir. $\mathrm{Bu}$ nedenle 29 Ekim Çameli depremi ve sonrası deprem yoğunluğunun analizinde mutlak odak lokasyonunu iyileştiren göreceli deprem yeri yöntemlerinden biri olan çift fark algoritması (hypoDD) [14] kullanılmıştır. Bu algoritma bir istasyonda gözlemlenen iki yakın olayın hareket sürelerindeki farkın, yüksek doğrulukta olaylar arasındaki mekansal sapmaya bağlanabileceğini varsaymaktadır.

\section{Materyal ve Metot}

Çameli Bölgesinde 2007 ve 2008 y1llarında yoğun deprem aktivitesi gözlenmiştir. Bu depremlerin arasında en büyüğü 29 Ekim 2007 (ML=5.1) tarihinde meydana gelen Çameli depremidir.

Şekil 4'de dalga şekli modellemesi [15] ile elde edilen Çameli depreminin kaynak özellikleri ve mekanizma çözümü, gözlemsel ve yapay sismogramların karşılaştırması görülmektedir. En iyi uyumun sağlandığı odak derinliği $4 \mathrm{~km}$ olarak tespit edilmiştir. Çameli depreminin fay düzleminin 1 . düzlem için doğrultu, eğim ve atım yönü surasıyla 100, 46, -96 ikinci düzlem için $289,44,-83$ derece olarak bulunmuş ve sismik moment değeri $\mathrm{Mo}=97.283$ (xe 22 dyncm) olarak hesaplanmıştır [6]. Çameli depremi fay çözümü dikkate alındığında KB-GD doğrultulu sol yanal oblik normal faylanma olduğu görülmektedir. Ana şok ve artçı şok aktivitesi benzer faylanma mekanizması sergilemektedir (Şekil 4). 


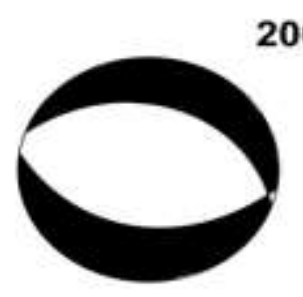

2007/10/29 Cameli 09:23

epsilon $=0.0648$ isotropic component $=-0.000$ variance reduction: $\mathbf{5 8 . 3 0 4}$ correlation: 0.666 best double couple: $\mathrm{Mo}=97.283$ (xe 22 dyncm) $M w=5.3$ tau $=1.2$ nodal planes (strike/dip/slip) $=100.18 / 46.23 /-96.38$ $289.37 / 44.14 /-83.38$ latitude longitude depth $\begin{array}{lll}37.033 & 28.233 & 4.000\end{array}$
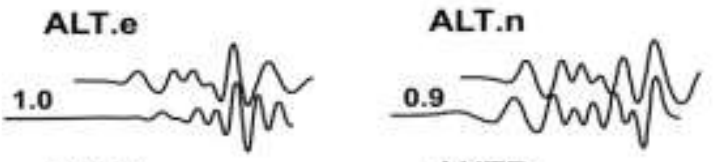

ALT.z
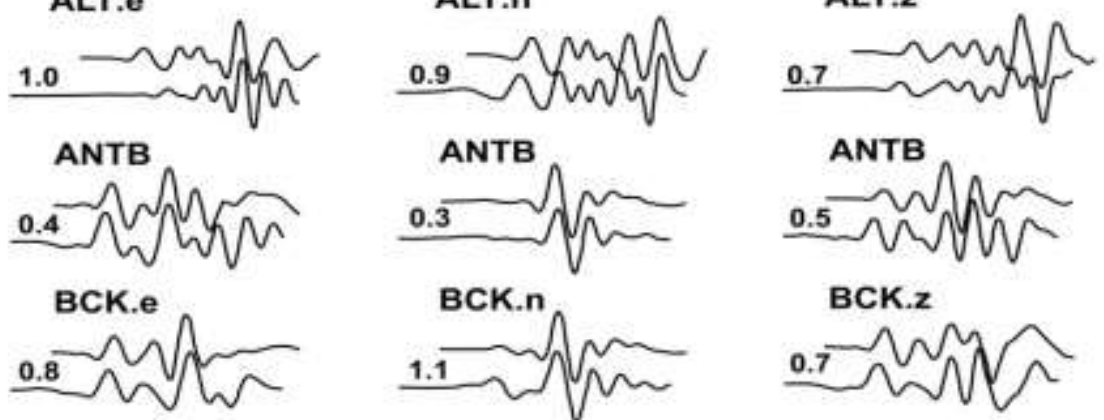

Syn
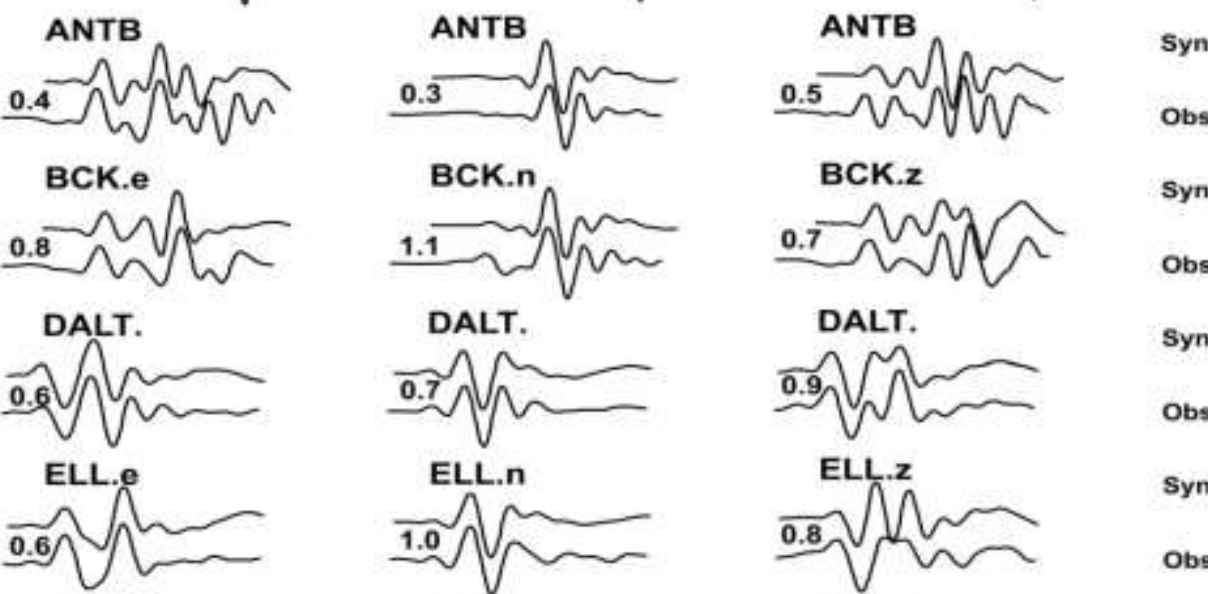

DALT.

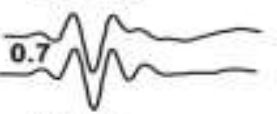

ELL.n

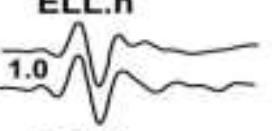

KULA.
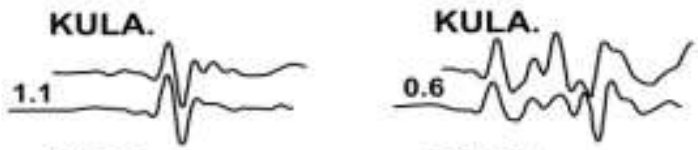

MLSB.

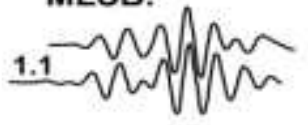

MLSB.

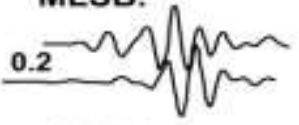

SHUT.
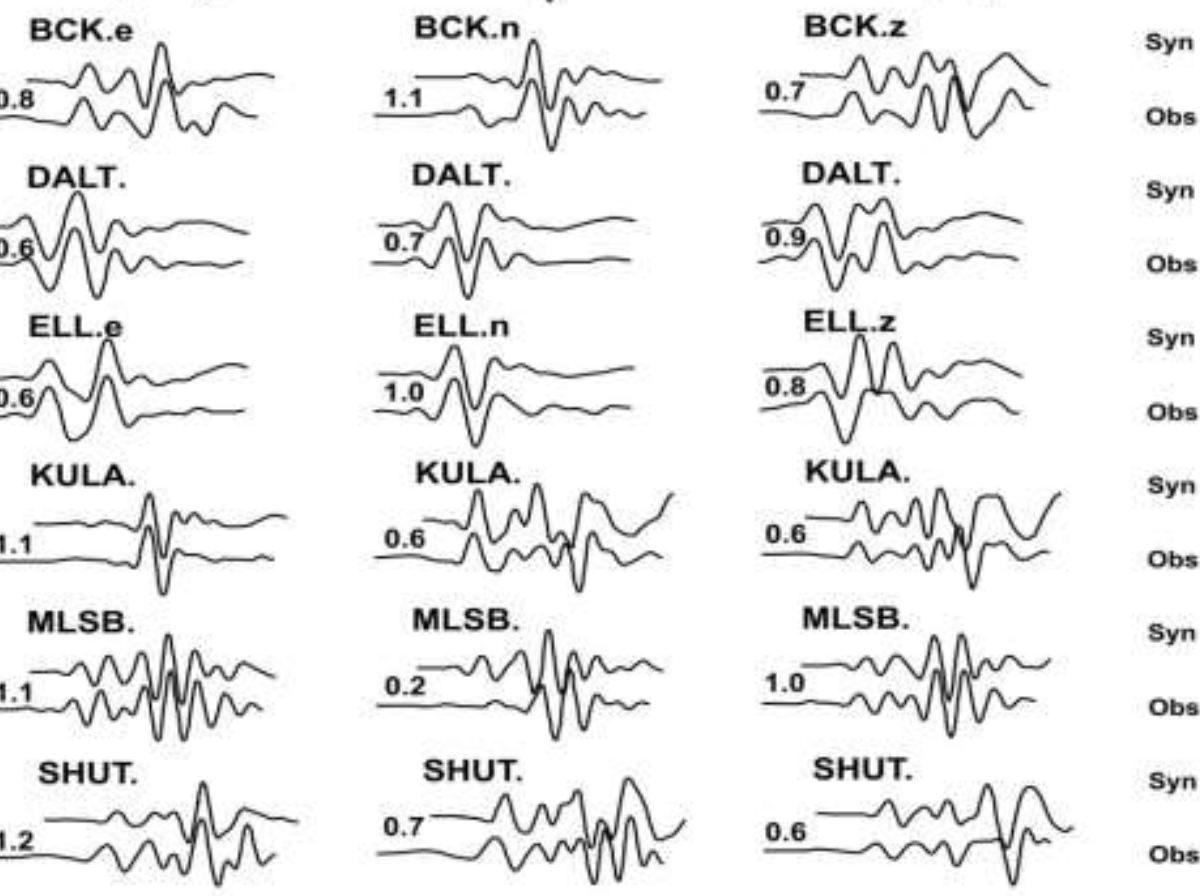

Syn

Obs

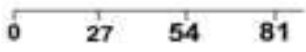

Şekil 4. 29 Ekim 2007 Çameli Depreminin sekiz geniş bant istasyonu için, yakın alan dalga formu kayıtlarını kullanan moment tensörünün ters çözümü sonucu. Odak mekanizması sol üst kısımda gösterilmiş ve kaynak parametreleri odak küresinin sağında gösterilmiştir. Her bir istasyondaki sentetik (üst) ve gözlenen (alt) sismogramlar, Doğu-Batı bileşeni (e), Kuzey-Güney bileşeni (n) ve dikey bileşen (z) için, iki sismogram arasında gözlenen ve sentetik genlik oranı ile gösterilmiştir [6].

Hypocenter programı ile konum parametreleri hesaplanırken hatalar minimize edilmeye çalışılsa da ağ geometrisi faz okuma hataları ve kabuk yapısı belirsizlikleri nedeniyle hatalar istenenden büyük olur. Burada hata miktarları yatayda ortalama $3.5 \mathrm{~km}$, düşeyde ise ortalama $7 \mathrm{~km}$ 'dir. $\mathrm{Bu}$ çalışmada çift fark algoritması (hypoDD) kullanılarak lokasyon parametrelerindeki hatalar minimize edilip, ağ geometrisi ve faz okuma kalitesi arttırılmıştır.

Ters çözüme giriş verisi olarak depremlerin mutlak konum parametreleri ve deprem çiftleri arasındaki $\mathrm{P}$ ve $\mathrm{S}$ dalgası seyahat zamanları farkı kullanılmıştır.

BDTIM tarafindan hazırlanan katalogdan 2007-2008 yılında meydana gelen Çameli merkez olmak üzere $50 \mathrm{~km}$ yarıçaplı alan içerisinde kalan 1206 deprem seçilmiştir. Depremler zSacWin [16] Programı kullanılarak BDTIMM tarafından çözümlenmiştir. Bu depremlerin ilksel konumları Şekil 5'de haritalanmıştır. 


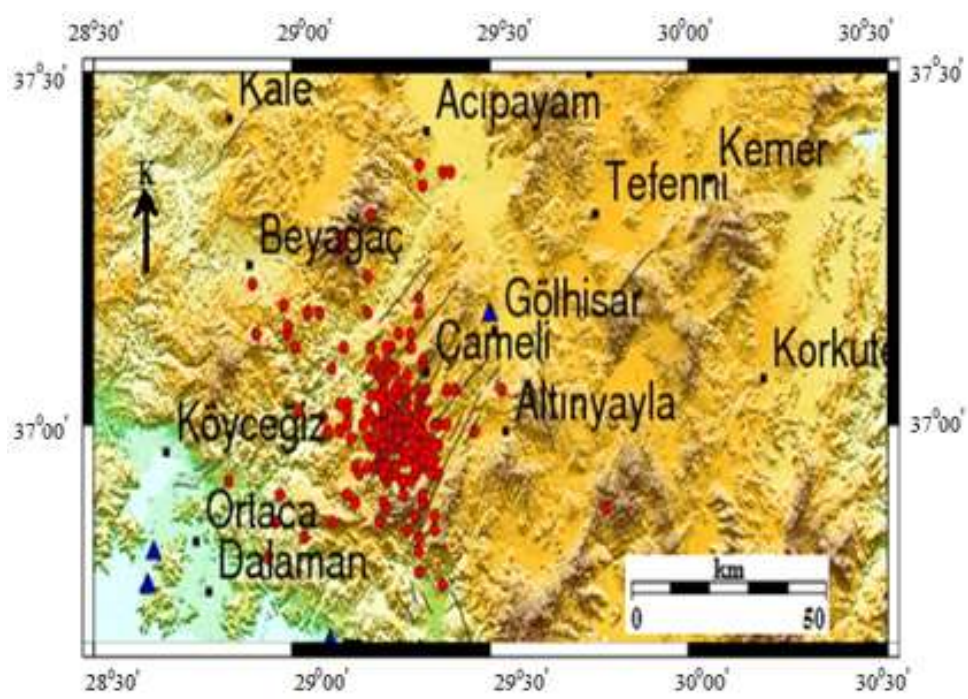

Şekil 5. BDTIMM'den alınan verilerinden elde edilen Çameli Bölgesi deprem dağılımı (hypoDD öncesi), mavi üçgenler istasyon konumlarını, kırmızı daireler deprem konumlarını temsil etmektedir.

TÜBITTAK ve AFAD'ın ortaklaşa yürüttükleri Deprem Sonrası Acil Gözlem Araştırmaları projesi kapsamında Çameli depremi sonrası devam eden deprem aktivitesini yaklaşı bir aylık süre boyunca izlemek için 4 Kasım 2008 tarihinde 10 adet deprem istasyonu kurulmuştur. İstasyonlar yapay kaynaklı sismik gürültünün çok düşük olduğu alanlara yerleştirilmiştir. Bu istasyonlarda Çameli bölgesine ait 754 adet deprem kaydedilmiştir. Kayıtlardaki depremlerin konumu, Hypocenter algoritmas [17] ile TÜBİTAK tarafindan belirlenmiştir. Her bir depreme ait odak koordinatlarını, oluş zamanlarını ve her bir istasyondaki varış zamanlarını içeren bir veri seti hazırlanmıştır. Bu veri setindeki olayların çok iyi konumlandırılabilir özellikte olması gerekmektedir. Kaliteli bir veri seti ile doğru sonuca ulaşılabilir ve elde edilen sonuçları güvenilir kılar. Bu nedenle veri seçimine önem verilmiştir. Seçilen depremlerin harita üzerindeki odak dağılımı Şekil 6' da gösterilmektedir.

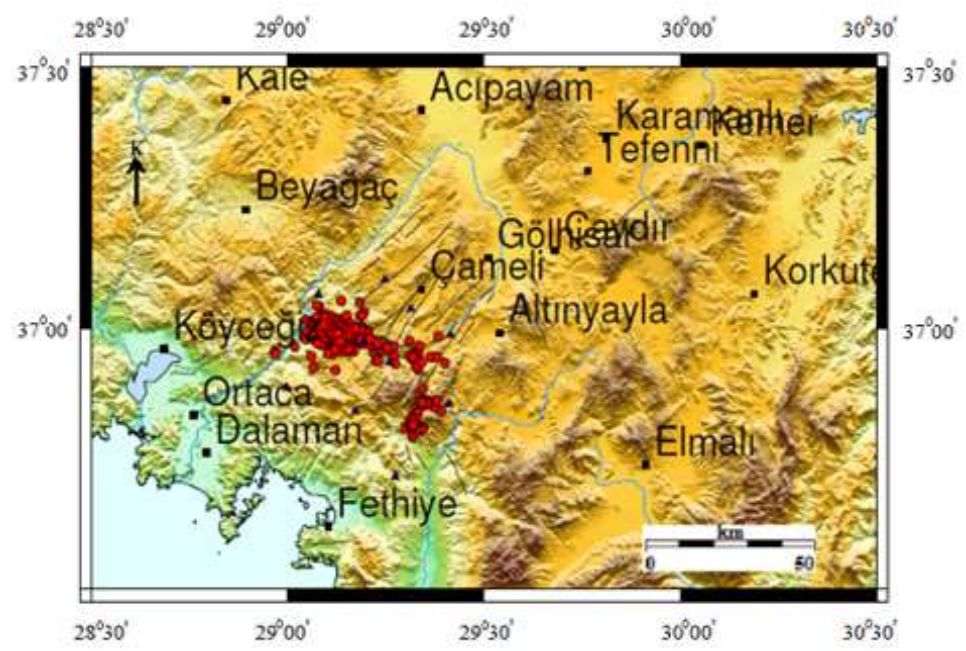

Şekil 6. Çameli Bölgesinde TÜBİTAK tarafindan kaydedilen depremlerin dağı̆ımı, artı işareti çalışma alanının orta noktasını, üçgenler istasyonları temsil etmektedir.

Depremlerin konum hatalarını azaltmak böylece daha güvenilir fay geometrisi bilgisi elde edebilmek için göreceli konum (hypoDD) yöntemi kullanılmıştır. Bu yöntem ile birbirine çok yakın deprem çiftleri için gözlenen ve teorik seyahat zamanı farklarının en küçüklenmesi ile depremlerin konumları iyileştirilmektedir. Çift-fark algoritmasında ilk adım, odaktan sismik istasyona olan seyahat zamanını belirlemektir.

$T_{k}^{i}=\tau^{i}+\int_{i}^{k} u d s$ 
$\mathrm{T}$, bir depremden (i), sismik istasyona (k) giden ışın yolu boyunca çizgi integrali olarak tanımlanan varış zamanıdır. $\tau^{i}$ depremin oluş zamanı, u yavaşlık alanı, ds ise ışın yolu uzunluğunun bir elemanidır.

Çift-fark algoritmasında seyahat zamanı rezidüellerini en küçüklemek için (minimize etmek ) tekil değer ayrışımı (SVD) ve eşlenik gradyan en küçük kareler (LSQR) yöntemleri kullanılır. SVD sadece küçük kümelerde kullanışlıdır, çok sayıda veri içeren büyük kümelerde sonuç vermez.

Büyük kümeleri veya çok sayıda küme yeniden konumlandırılırken SVD yerine LSQR [18] kullanılır. Bu çalışmada çok sayıda deprem verisi olduğu için çözümde LSQR yöntemi kullanılmıştır.

Çift-fark yönteminin temelini iki deprem arasındaki mesafenin, kaydedildikleri ortak istasyona olan uzaklıklarından küçük olması durumunda kaynaktan istasyona olan 1şın yollarının benzer olduğu kabulüne dayanmaktadır [14]. Depremlerin ilksel konum bilgileri, P, S dalgası seyahat zamanları ve çalışma bölgesinin bir boyutlu hız modeli hypoDD programının giriş verisi olarak kullanılır. $\mathrm{Bu}$ çalışmada Ege Bölgesi için belirlenen bir boyutlu hız modeli [19] kullanılmıştır (Tablo 2). Çift fark ters çözümünde parametrelerin seçimi aşamasında istatistiksel bir yaklaşım [20] kullanılmıştır.

Tablo 2. Bu Çalışmada kullanılan P dalgası (Vp) hız modeli [19]

\begin{tabular}{|c|c|}
\hline Derinlik $(\mathrm{km})$ & $\mathrm{Vp}(\mathrm{km} / \mathrm{s})$ \\
\hline $0.0-1.5$ & 4.7 \\
$1.5-3.0$ & 5.1 \\
$3.0-5.0$ & 5.8 \\
$5.0-15.0$ & 6.0 \\
$15.0-21.0$ & 6.3 \\
$21.0-29.0$ & 6.4 \\
$29.0-$ & 7.8 \\
\hline
\end{tabular}

\section{Bulgular ve Tartışma}

BDTIM tarafından çözümü yapılan depremlerin $\mathrm{P}$ ve $\mathrm{S}$ fazlarına ait seyahat zamanı bilgileri kullanılarak hypoDD [14] programıyla yeniden konumlandırılmıştır. BDTIMM tarafından yerleştirilen ve Çameli bölgesindeki depremleri kaydeden sismometrelerin çoğunun çalışma alanına 100 km' den uzak olması nedeniyle yatayda ve düşeyde $7400 \mathrm{~m}$ ' ye varan yüksek hatalar çıkmıştır bu nedenle bu depremler değerlendirmeye alınmamıştır. Bu veri grubundan hypoDD programıyla sadece 50 adet depremin tekrar konumlandırılması yapılmıştır (Şekil 7). Elde edilen kümeler daha dar bir alanda sıkışmış ve hizalanmıştır. Depremler 5 ile $15 \mathrm{~km}$ arasında yoğunlaşmıştır.

Şekil 7' de BDTIMM tarafindan kaydedilen depremlerin hypoDD sonrası gösterilen deprem dağılımında 3 farklı kümelenme dikkat çekmektedir. Bu kümelenmelerin doğrultuları KD-GB şeklindedir.
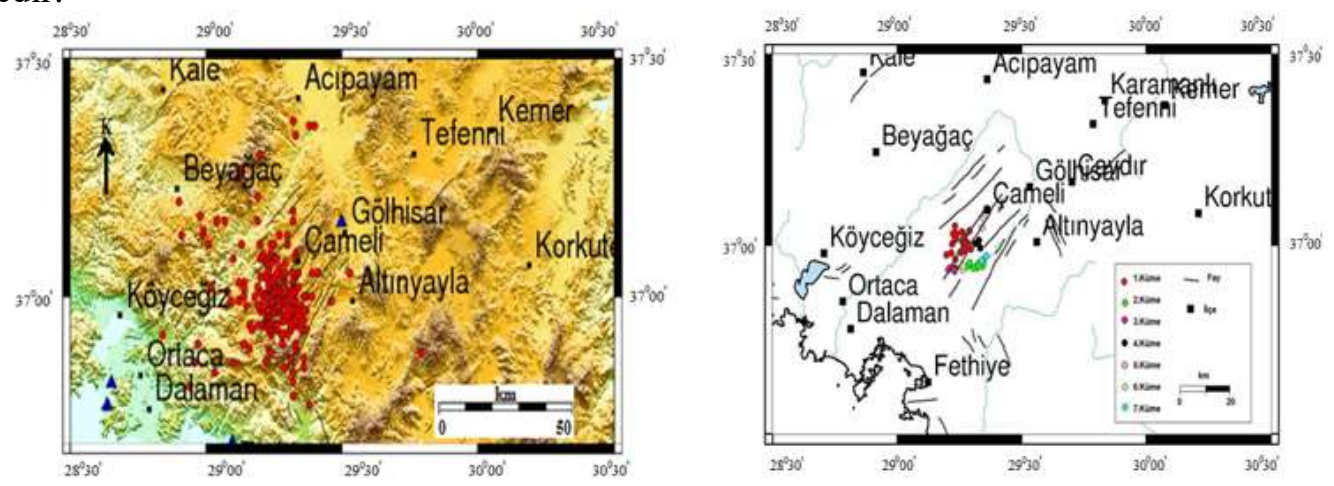

Şekil 7. Boğaziçi Üniversitesi Kandilli Rasathanesi Deprem Araştırma Enstitüsü Ulusal Deprem İzleme Merkezi (BDTIM)' nden alınan deprem verilerinin (solda) göreceli lokasyon yöntemi sonucu elde edilen kümelerin konumları (sağda) 


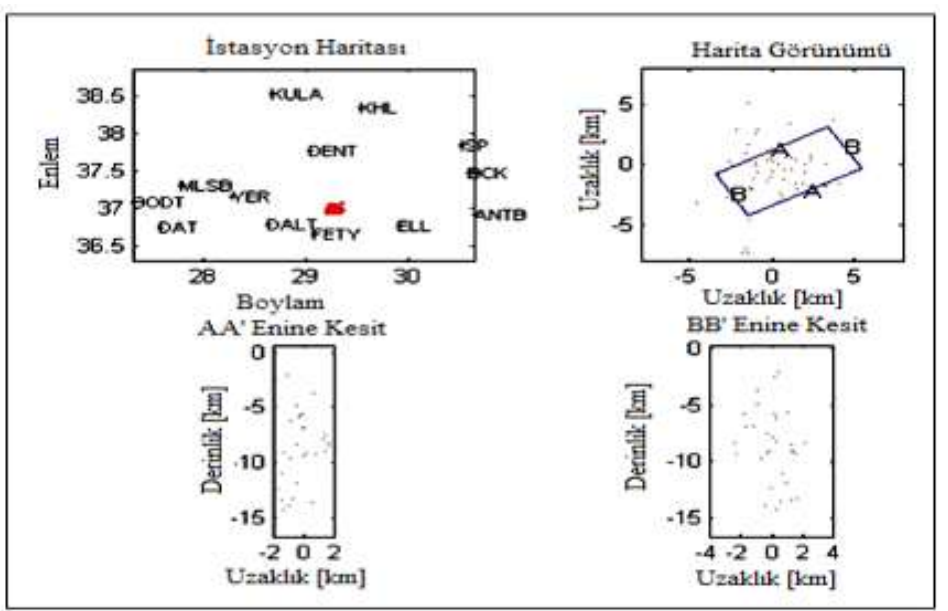

Şekil 8. BDTIM' den alınan deprem verilerinin göreceli lokasyon yöntemi sonucu elde edilen derinlik kesitleri.

Depremselliğin derinlikle değişiminde (Şekil 8) deprem dağılımının sığ derinliklerle sınırlandığ1 görülmektedir. Fakat bu çalışmada çok küçük büyüklüklerdeki depremler de incelendiğinden deprem dağılımının $14 \mathrm{~km}$ derinliğe kadar indiği görülmektedir.

TÜBITTAK verilerinin hypoDD analizi ile yaklaşık 686 depremin konumu iyileştirilmiştir (Şekil 9). Yatay hatalar (Ex ve Ey) sırasiyla $100-800 \mathrm{~m}$ ve 150-900 m arasında ve düşey hata ise 100-900 m arasında değişmektedir. Depremlerin konumları çift fark yöntemi ile daha belirgin hale gelmiştir. İyileştirilen deprem derinlikleri sismojenik kabuk kalınlığını belirlemede yardımcı olmuştur (Şekil 10).

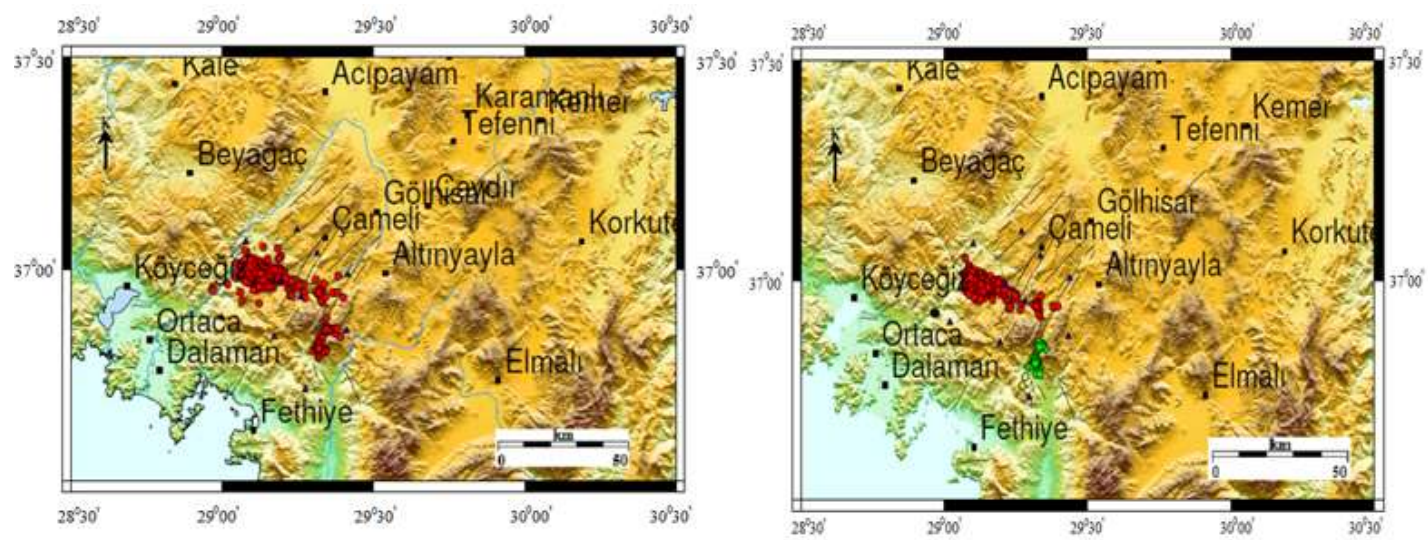

Şekil 9. TÜBİTAK' tan alınan depremlerin (solda) göreceli lokasyon yöntemi sonucu elde edilen konumları (sağda), mavi üçgenler istasyon konumlarını, kırmızı daireler 1. büyük kümeyi, yeşil ve siyah daireler ise sirasıyla 2. ve 3. küçük kümeleri temsil eder.
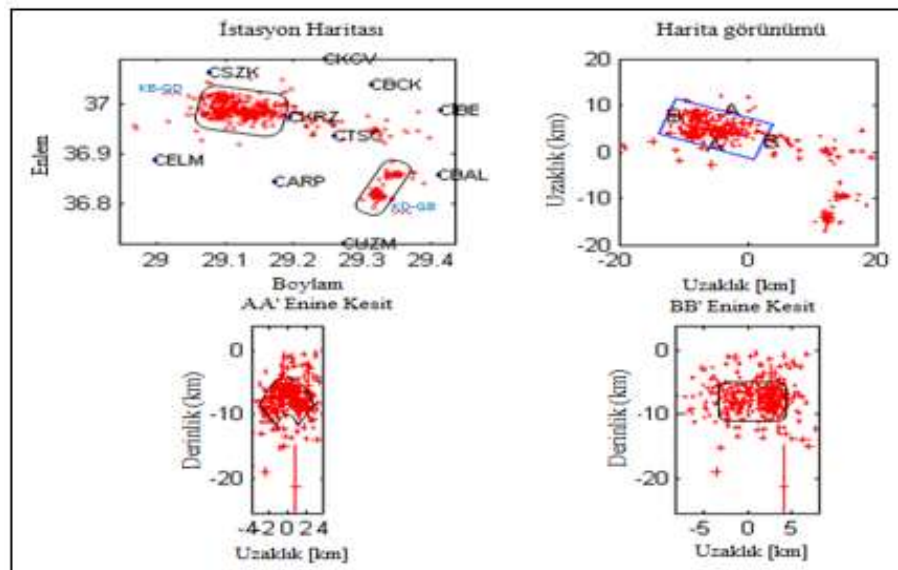

Şekil 10. TÜBİTAK'tan alınan deprem verilerinin hypoDD sonrası elde edilen derinlik kesitleri 
TÜBITAK ve BDTIMM sonuçları (Şekil 11 ) karşılaştırıldığında birbirine dik iki yönelim görülür. TÜBİTAK verilerinde kırmızı renkli büyük küme KB- GD yönelimli ve depremler bölgedeki fayların uç kısmında gözlenmektedir. BDTİM verilerinde ise nispeten büyük 3 kümenin yönelimi KD-GB olup depremler fay dizileri üzerindedir.

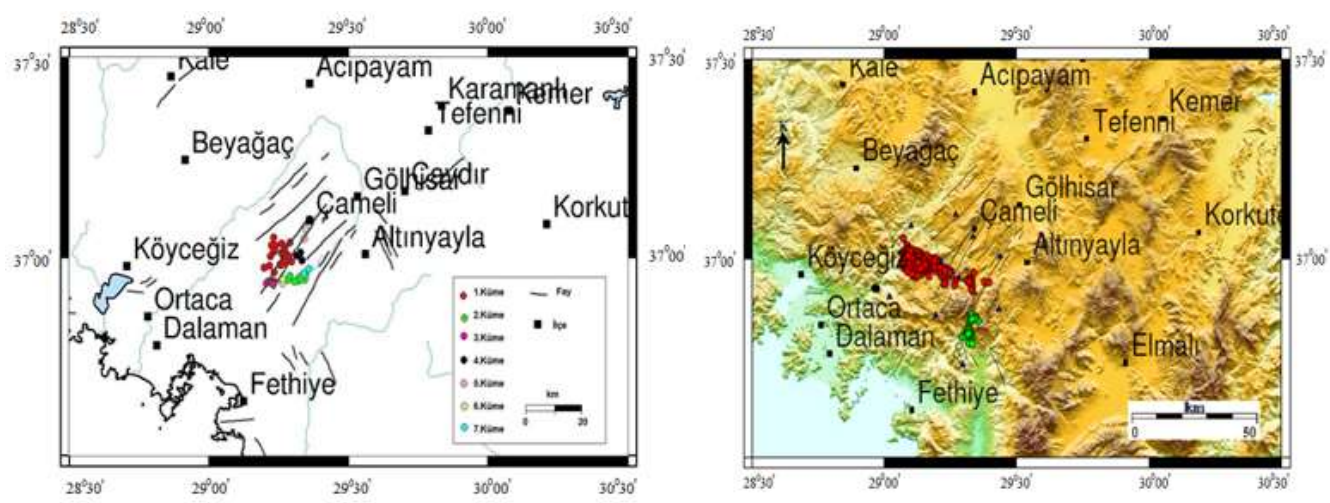

Şekil 11. BDTIM' den alınan depremlerin hypoDD sonrası elde edilen konumları (solda) ve TÜBİTAK'tan alınan depremlerin hypoDD sonrası elde edilen konumları (sağda)

TÜBİTAK ve BDTIM sonuçlarında derinlik kesitleri incelendiğinde; BDTIMM deprem dağılımı 14 km' ye kadar iken TÜBITTAK deprem dağ 11 mı 16 km'ye kadar inmiştir. Şekil 10'da büyük kümenin enine ve boyuna derinlik kesitleri incelendiğinde depremselliğin yarı oval dar bir alanda meydana geldiği görülmektedir.
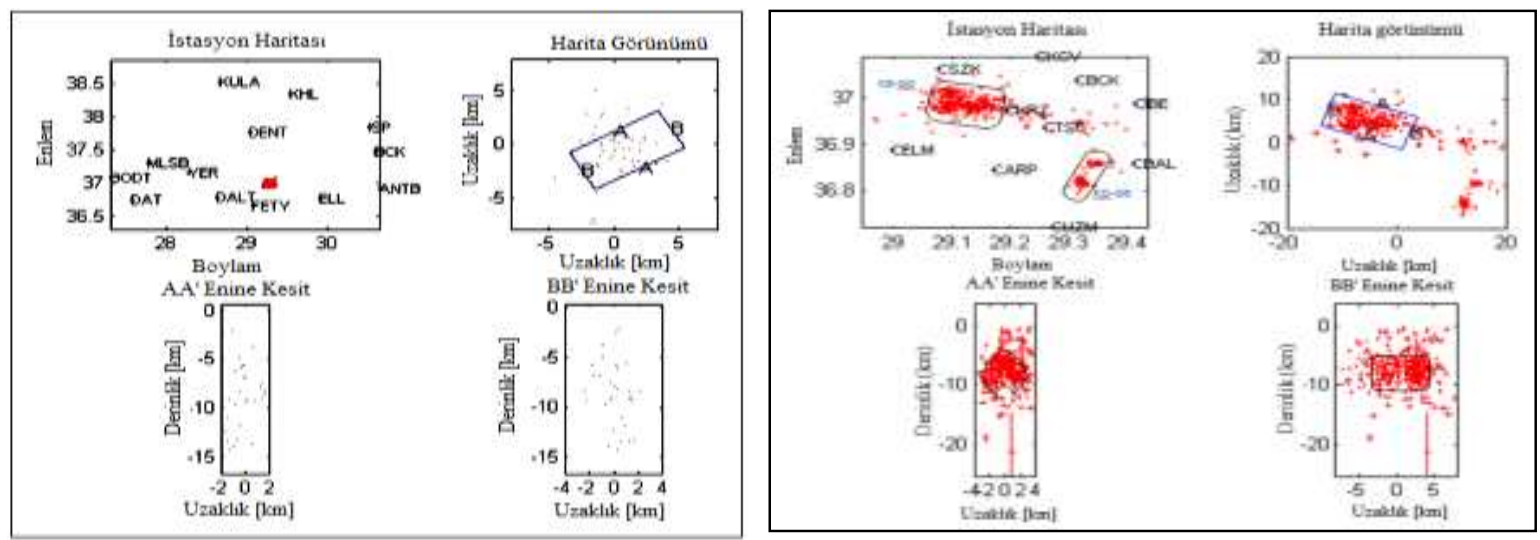

Şekil 12. BDTİM (solda) ve TÜBİTAK'tan (sağda) alınan depremlerin göreceli lokasyon yöntemi sonucu edilen derinlik kesitleri

\section{Sonuç ve Öneriler}

Bu çalışmada 29 Ekim 2007 tarihinde meydana gelen Çameli Depremi ve artçı şokları çift fark algoritması ile analiz edilmiştir. Çalışmada BDTIM' den alınan 2007-2008 yılında meydana gelen Çameli merkez olmak üzere $50 \mathrm{~km}$ yarıçaplı alana isabet eden 1206 adet deprem ve TÜBİTAK' dan alınan 4 Kasım 2008 - 5 Aralık 2008 tarihleri arasında meydana gelen Çameli bölgesine ait 754 adet deprem kullanılmıştır. BDTIMM tarafindan yerleştirilen sismometrelerin çalışma alanına 100 km' den uzak olması nedeniyle verilerin çift-fark yöntemi ile yeniden konumlandırılması sonucu yatay ve düşey düzlemde hatalar yüksek çıkmış ve veri sayısı azalmıştır. Yalnızca 50 adet depremin tekrar konumlandırılması yapılmıştır. HypoDD sonrası elde edilen kümeler daha dar bir alanda sıkışmış ve hizalanmıştır. Depremler 5 ile $15 \mathrm{~km}$ arasında yoğunlaşmıştır.

Şekil 9'da TÜBİTAK' tan alınan deprem verilerine çift-fark yöntemi uygulanmadan önceki ilksel konumları ve çift-fark yöntemi ile elde edilen sonuçlara göre depremlerin dağılımı gösterilmektedir. HypoDD sonrası deprem dağılımı büyük bir kümelenme etrafında az sayıda deprem bulunan küçük kümelerden oluşmaktadır. KB-GD' doğrultusunda uzanan depremsellik (büyük küme) incelendiğinde ilksel konumlara göre daha net bir görüntü ortaya çıkmıştır. Çameli depreminin fay 
çözümü dikkate alındığında KB-GD doğrultulu sol yanal oblik normal faylanma olduğu görülmektedir. İyileştirilen deprem odak yerlerinin moment tensör çözümleri ile uyumlu olması dikkat çekicidir. Depremlerin bu dağılımı Över vd. [6]'nin önerdiği, Çameli Bölgesi'nin Kıbrıs Yayı boyunca olan dalma batma zonunun neden olduğu KB-GD yönlü açılıma maruz kaldığı hipotezi ile uyumludur. Bu büyük kümedeki depremler çizgiselleşmeye benzer dar bir alana yayılmışlardır. Bu küme içindeki depremler yaklaşı $2 \mathrm{~km}$ ve $15 \mathrm{~km}$ derinlikleri arasında yoğunlaşmaktadır (Şekil 10). Çameli bölgesi için sismojenik kabuğun alt sınırı yaklaşık 15 km olduğu düşünülebilir.

\section{Teşekkür}

Deprem verileri için TÜBITTAK ve BDTIM' e çok teşekkür ederim. Prof. Dr. Ali Pınar, Prof. Dr. Asım Oğuz Özel, Dr. Doğan Kalafat, Doç. Dr. Onur Tan ve Doç. Dr. Özcan Bektaş’a yapıcı eleştirileri ve önerileri için çok teşekkür ederim. Haritalar, Genel Haritalama Araçları (GMT) ile çizildi [21].

\section{Yazarların Katkısı}

Makalede tüm katkı şahsıma aittir.

\section{Çıkar Çatışması Beyanı}

Yazarlar arasında herhangi bir çıkar çatışması bulunmamaktadır.

\section{Araştırma ve Yayın Etiği Beyanı}

Yapılan çalışmada, araştırma ve yayın etiğine uyulmuştur.

\section{Kaynaklar}

[1] Gürer A., Bayrak M., Gürer Ö.F. 2004. Magnetotelluric images of the crust and mantle in the southwestern Taurides, Turkey. Tectonophysics, 391:109-120.

[2] Alçiçek M.C., Kazancı N., Özkul M. Sen S. 2004. Çameli (Denizli) Neojen havzasının tortul dolgusu ve jeolojik evrimi. Maden Tetkik ve Arama Dergisi, 128: 99-123.

[3] Alçiçek M.C., Kazancı N., Özkul M. 2005. Multiple rifting pulses and sedimentation pattern in the Çameli Basin, southwestern Anatolia, Turkey. Sedimentary Geology, 173: 409-431.

[4] Alçiçek M.C., Ten Veen J.H.T., Özkul M. 2006. Neotectonic development of the Çameli Basin, southwestern Anatolia, Turkey. In: Robertson, A.H.F., Mountrakis, D. (Eds.), Tectonic Development of the Eastern Mediterranean Region, Geological Society, London, Special Publications, 260: 591-611.

[5] Alçiçek M.C. 2001. Çameli Havzası'nın Sedimantolojik İncelemesi (Geç Miyosen-Geç Pliyosen, Denizli, GB Anadolu). Doktora Tezi, Ankara Üniversitesi, Fen Bilimleri Enstitüsü, 101s, Ankara.

[6] Över S., Özden S., Pınar A., Yılmaz H., Ünlügenç U.C., Kamacı Z. 2010. Late Cenozoic Stress Field in the Cameli Basin, SW Turkey. Tectonophysics, 492 (4): 60-72.

[7] Elitez İ., Yaltırak C. 2014. Çameli Havzası'nın Miyosen-Kuvaterner Jeodinamigi, Burdur-Fethiye Makaslama Zonu (GB Türkiye). Geological Bulletin of Turkey, 57: 3.

[8] Şaroğlu F., Emre Ö., Boray A. 1987 Türkiye'nin diri fayları ve depremsellikleri. MTA Derleme, 8174: 394.

[9] Eyidoğan H., Utku Z., Güçlü U., Değirmenci E. 1991. Türkiye Büyük Depremleri Makro-Sismik Rehberi (1900-1988). İ.T.Ü. Maden Fakültesi, Jeofizik Mühendisliği Bölümü, 198.

[10] Demirtaş R., Erkmen C., Yaman M. 2000. 12 Kasım 1999 Düzce Depremi: Yüzey Kırık Geometrisi, Atım Miktarı Dağılımı ve Gelecek Deprem Potansiyeli, Deprem Araştırma Dairesi. Afet İşleri Genel Müdürlüğ̈̈, 61-99, Ankara.

[11] Dewey J.F., Şengör A.M.C. 1979. Aegean and surrounding regions complex multiplate and continuum tectonics in a convergent zone. Geological Society America Bulletin, 90 (383): 84-92. 
[12] Koçyiğit A., Ünay E., Saraç G. 2002. Episodic graben formation and extensional neotectonic regime in West Central Anatolia and the Isparta Angle: a case study in the Aksehir-Afyon Graben, Turkey. Geological Society, London, Special Publications, 173: 405-421.

[13] Canbay E. 2009. Fethiye -Burdur Fay Kuşağının Güneybatı Uzantısının Kinematik Özellikleri.İstanbul Üniversitesi, Fen Bilimleri Enstitüsü, Yüksek Lisans tezi, 63 s, İstanbul.

[14] Waldhauser F., Ellsworth W.L. 2000. A double-difference earthquake loca-tion algorithm: method and application to the northern Hayward fault, California. Bulletin of the Seismological Society of America, 90: 1353-1368.

[15] Kuge K. 2003. Source modeling using strong-motion waveforms: toward automated determination of earthquake fault planes and moment-release distributions. Bulletion of Seismological Society of America, 93: 639-654.

[16] Yilmazer M. 2003. Online determination of earthquake source parameters using a new software zSacWin. MSc Thesis, University of Istanbul, Istanbul.

[17] Lienert B.R.E., Havskov J. 1995. A computer program for locating earthquakes both locally and globally. Seismological Research Letters, 66: 26-36.

[18] Paige C.C., Saunders M.A. 1982. LSQR: Sparse linear equations and least squares problems. ACM Transactions on Mathematical Software, 8 (2): 195-209.

[19] Akyol N., Zhu L., Mitchell B.J., Sözbilir H., Kekovalı K. 2006. Crustal structure and local seismicity in western Anatolia. Geophysical Journal International, 166: 1259-1269.

[20] Tan O., Tapırdamaz M.C., Ergintav S., Inan S. 2010. Bala (Ankara) earthquakes: Implications for shallow crustal deformation in Central Anatolian Section of the Anatolian Platelet (Turkey). Turkish Journal of Earth Sciences, 19: 449-471.

[21] Wessel P., Smith W.H.F. 1998. New, improved version of the Generic Mapping Tools released, Eos Trans. AGU, 79 (47): 579. 